\title{
FEM Modeling of Delamination in AS4/PEEK Thermoplastic Composites Under Mixed - Mode Bending Test
}

\author{
Viorel IONESCU \\ Department of Physics and Electronics, Ovidius University, Constanta, 900527, Romania, \\ E-mail:ionescu.vio@gmail.com
}

cross'ref http://dx.doi.org/10.5755/j01.mech.26.2.24183

\section{Introduction}

In aircraft industry, thermoplastic composites like the AS4 carbon fiber reinforced poly-ether-ether-ketone (AS4/PEEK) are used in structural applications: leading edges, clips and brackets, and stiffened thermoplastic panels $[1,2]$. Recently, AS4/PEEK composites became very attractive for orthopedic implants, due to biocompatibility, similar modulus to bone and ability to withstand prolonged fatigue strain $[3,4]$.

Under static and fatigue loadings, composite laminates suffer delamination failure $[5,6]$, due to an adjacent layer's separation in laminates composites. This phenomenon can cause a severe degradation of the load-bearing characteristics for composite laminate. Low energy impact damage is one of the most important events responsible for internal degradation of composite laminates, due to a complex mixture of delamination, matrix cracking and fiber failure. Transverse ply cracks may develop owing to residual stresses or machining damage during manufacture, or under service loads, producing high localized stresses where they meet plies of different orientations, which may cause delamination at the ply interfaces [7].

The double cantilever beam test (DCB) represent one of the main methods used for the study of interlaminar fracture behavior, with evaluation of critical strain energy release rate $G_{C}$ in laminar composites having initial precracks [8]. Usually, delamination initiates and propagates due to combined effect of normal and shear stresses and from this reason failure testing must include a combined tensile normal stress (mode I) and sliding shear stress (mode II). Mixed-mode bending (MMB) test was developed in order to combine DCB mode I loading and end-notch fixture (ENF) mode II loading by evaluating total strain energy rate $G_{T}$ with its mode I $\left(G_{I}\right)$ and mode II $\left(G_{I I}\right)$ [9]. A wide range of $G_{I I} / G_{T}$ ratios can be produced by modifying the load position on the lever inside the testing system, starting from $G_{I I} / G_{T}=0 \%$ (DCB) till $G_{I I} / G_{T}=100 \%$ (ENF).

In order to simulate the fracture initiation and propagation in composite laminates, several specialized numerical schemes under the frame work of Finite Element Method (FEM) have been developed. The virtual crack closure technique (VCCT) was used for the study of the pre-crack length effect on the mode I critical energy release rate $G_{I C}$ in woven GFRP (Glass Fiber Reinforced Polymer) composites under DCB test using a FEM based software, Ansys 15, along with experimental investigations and it was demonstrated that pre-cracks with length higher than $57 \mathrm{~mm}$ had no influence on $G_{I C}$ value at room temperature [10]. The Cohesive Zone (CZM) model offer a good prediction ability of interfacial delamination, of matrix crack and even fiber break under static loads [11, 12]. CZM is based on the concept of bounded stress within an extended crack tip, or cohesive zone were delamination is developed [13]. Camanho et al. [14] implemented a CZM based method for simulating progressive delamination on single-mode and mixed-mode delamination test specimens with pre-existing cracks, and this approach was also considered in the present study, developed using Comsol Multiphysics software.

Comsol Multiphysics represents sometimes a better choice than ANSYS software for numerical studies in materials engineering, due to its multiphysics analysis capabilities, by modeling and simulating the interplay between the structural and thermal problem for any type of material. For example, Comsol present a superior description of hyper-elastic materials by providing directly the validated constitutive equations. Comsol has also the ability to develop your own physics in the form of partial differential equations (PDE) for any physical problem.

Ultrasonic wave phenomena constitute the leading physical mechanism for nondestructive evaluation (NDE) and structural health monitoring (SHM) of solid composite materials such as carbon-fiber-reinforced polymer (CFRP) laminates, and guided-wave simulations for CFRP composites implemented with Comsol and ANSYS codes offered an experimental accuracy of $10.8 \%$ and $8.5 \%$, respectively, for the group velocity values along to $0^{\circ}$ fiber orientation inside the out-of-plane velocity wavefield on the composite surface[15].

\section{Model formulation}

The criteria used in this study in order to predict delamination propagation in laminate composites was the mixed-mode criterion proposed by Benzeggagh and Kenane [16], critical energy release rate $G_{C}$ being expressed as a function of the Mode I and Mode II fracture toughness and considering an exponent $\eta$ obtained from MMB tests, defining the failure locus under mixed mode loading:

$$
G_{C}=G_{I C}+\left(G_{I I C}-G_{I C}\right)\left(\frac{G_{I I}}{G_{T}}\right)^{\eta}
$$

where: $G_{T}=G_{I}+G_{I I}$.

When the energy release rates $G_{I}$ and $G_{I I}$ became equal with the corresponding fracture toughness of the material $\left(G_{I c}, G_{I I c}\right)$ we can predict the delamination propagation.

The beam-theory analysis conducted to the following expressions for $G_{I}$ and $G_{I I}$ under the MMB specimen loading test [9]: 


$$
\begin{aligned}
& G_{I}=\frac{3 a P^{2}}{4 b^{2} h^{3} l^{2} E_{11}}(3 c-l)^{2}, \\
& G_{I I}=\frac{9 a P^{2}}{16 b^{2} h^{3} l^{2} E_{11}}(c+l)^{2},
\end{aligned}
$$

where: $E_{11}$ is the lamina longitudinal modulus, $\mathrm{GPa} ; a$ is the delamination length, $\mathrm{mm} ; P$ is the applied load, $\mathrm{N} ; b$ is the specimen width, $\mathrm{mm} ; h$ is half-thickness of the specimen, $\mathrm{mm} ; l$ is the specimen half span, $\mathrm{mm} ; c$ is the position of the applied load on the lever, mm, established through expression [14]:

$$
c=\frac{l\left(\frac{1}{2} \sqrt{3\left(\frac{1-k}{k}\right)}+1\right)}{3-\frac{1}{2} \sqrt{3\left(\frac{1-k}{k}\right)}} .
$$

The mode mixing ratio $k$ from relation (4) is expressed as a function of the energy release rates as [14]:

$$
k=\frac{G_{I I}}{G_{I}+G_{I I}} .
$$

Neglecting the weight of the lever, the middle and end loads, $P_{m}$ and $P_{e}$, are obtained as a function of the total load $P$ as [14]:

$$
\begin{aligned}
& P_{m}=P\left(\frac{c+l}{l}\right), \\
& P_{e}=P\left(\frac{c}{l}\right) .
\end{aligned}
$$

Numerically calculated pure mode displacement components, $u_{I}$ and $u_{I I}$ offer the possibility of evaluating the load-point displacement $u_{L P}$ with the following expression [14]:

$$
u_{L P}=\left(\frac{3 c-1}{4 l}\right) u_{I}+\left(\frac{c+l}{l}\right) u_{I I} \text {, }
$$

with mode II displacement component $u_{I I}$ calculated as a function of the displacement at the middle of the MMB test specimen $u_{M}$ for $a<l[14]$ :

$$
u_{I I}=u_{M}+\frac{1}{4} u_{I}
$$

A detailed description of the numerical model formulation which combines the CZM approach with the Arbitrary Lagrangian - Eulerian (ALE) methodology in the framework of Comsol Multiphysics software is presented elsewhere [17].

All the equations governing Solid Mechanics interface from Comsol Multipysics software are presented in detail in a previous study [18].
The isotropic damage model used in this paper in order to study the damage propagation in composite structures, as an extension to the build-in functionality of Comsol Multiphysics, is described in details elsewhere [19, 20]. A damage evolution function $\omega(\alpha)$, which determines the shape of stress-strain relationship, is expressed as a function of an internal variable $\alpha$ that keeps track of the current damage threshold [20]:

$$
\omega(\alpha)=\left\{\begin{array}{cc}
0 & \text { if } \alpha \leq \varepsilon_{0} \\
1-\frac{\varepsilon_{0}}{\alpha} \cdot \exp \left(\frac{\alpha-\varepsilon_{0}}{\varepsilon_{f}}\right) & \text { if } \alpha>\varepsilon_{0}
\end{array}\right. \text {, }
$$

where: $\varepsilon_{0}=0.016$ is the unidirectional AS4/PEEK composite strain at maximum tensile strength [21] and $\varepsilon_{f}$ is a material parameter that controls the initial slope of the softening curve (decaying rate of the material strength), defined by relation $[19,20]$ :

$$
\varepsilon_{f}=\frac{G_{C}}{N \cdot l_{c h}}+\frac{\varepsilon_{0}}{2},
$$

with $l_{c h}$ as the local finite element size.

A preliminary grid sensitivity test was performed in order to establish an optimal dimension for mesh elements that would yield sufficiently accurate results. For this purpose, the stored energy density $\left(\mathrm{MJ} / \mathrm{m}^{3}\right)$ was computed for a ratio $G_{I I} / G_{T}=50 \%$ along the delamination interface at a maximum load point displacement of $5 \mathrm{~mm}$ for the beam upper ply, for finite elements of constant length and different widths " $d$ ": 1.5, 1.75, 2, 2.25 and $2.5 \mathrm{~mm}$ (Fig. 1). The laminate material properties and geometric dimensions of the beam under simulation were considered from an experimental study [22]. Some details regarding the mesh network elements inside the beam model (with different element sizes) are presented in Table 1.

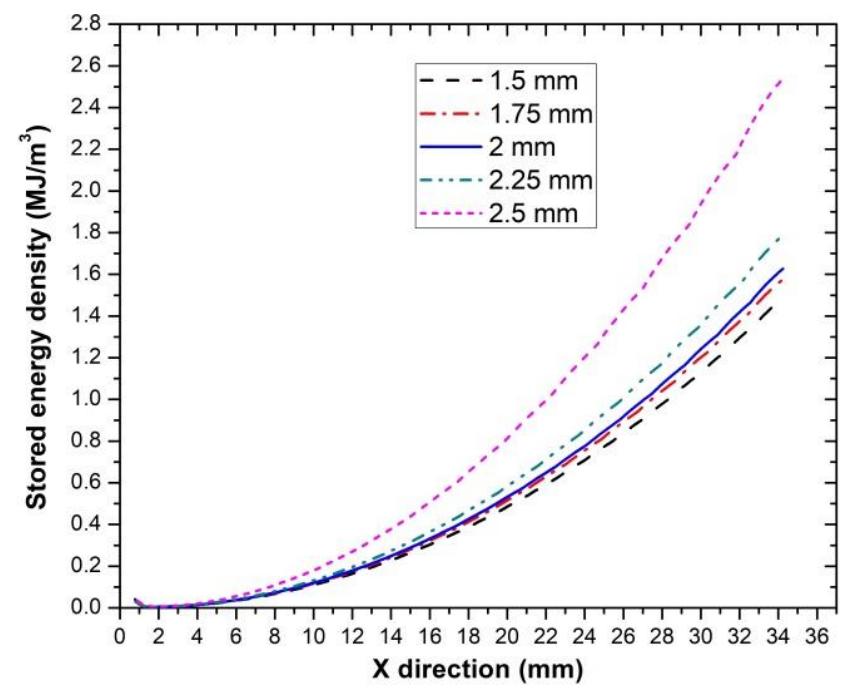

Fig. 1 Grid sensitivity test results in terms of stored energy density variation along the delamination interface length for different FE widths

The mesh network for the model discretization was based on a surface map with four rows quad finite elements (of width $d$ ) along the beam length ( $x$ direction). In the left part of the map (from the beam center till the crack right 
boundary) was considered another area of quad elements having a width of $d / 2$ (Fig. 2). Two solid elements were used constantly through the thickness of each of the two layers forming the beam [23]. It was applied here a symmetry boundary condition by modeling only half of the beam.

Table 1

Mesh statistics for the model after grid sensitivity test

\begin{tabular}{|c|c|c|c|c|c|}
\hline $\begin{array}{c}\text { FE width, } \\
\text { mm }\end{array}$ & 1.5 & 1.75 & 2 & 2.25 & 2.5 \\
\hline $\begin{array}{c}\text { Number of } \\
\text { hexahedron } \\
\text { elements }\end{array}$ & 1280 & 1120 & 976 & 880 & 784 \\
\hline $\begin{array}{c}\text { Number of } \\
\text { quad } \\
\text { elements }\end{array}$ & 1984 & 1744 & 1528 & 1384 & 1240 \\
\hline $\begin{array}{c}\text { Element vol- } \\
\text { ume ratio }\end{array}$ & 0.4899 & 0.4957 & 0.5068 & 0.4764 & 0.4955 \\
\hline
\end{tabular}

After grid resolution test presented in Fig. 1, in order to save computing time and memory, it was decided that the present numerical models to be meshed with maximum element sizes of $2 \mathrm{~mm}$, as we could see in Fig. 2, with finite element discretization statistics included in the inset of this figure.

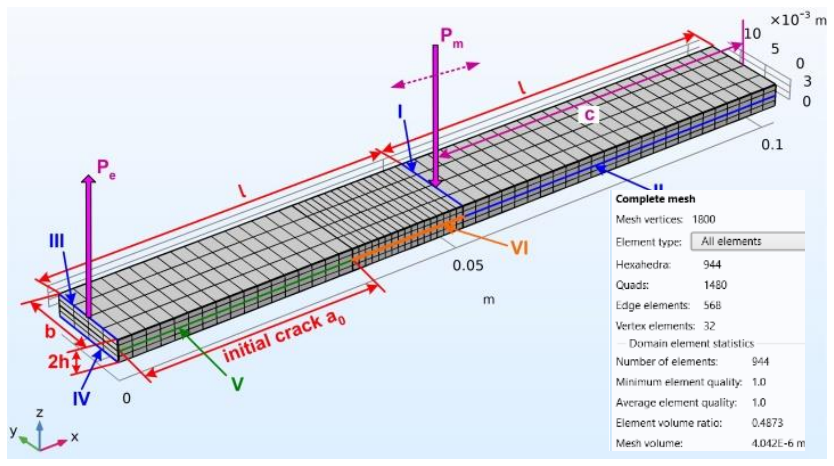

Fig. 2 Discretization network image with different mesh elements for the beam numerical model, presenting also the specimen geometrical characteristics and different model boundaries: I - middle edge, II - contact pair interface, III - cracked edge, IV - roller edge, V - delamination interface, VI - damage interface

\section{Results and discussions}

The experimental MMB tests for a 24-ply unidirectional AS4/PEEK composite samples with the fiber volume content of $60 \%$ have been performed by A. Turon et al. [22]. The specimens contained a Kapton film delamination starter at one end of the structure, with a thickness of $13 \mu \mathrm{m}$, located at the specimen mid-plane. It was established the initial delamination length of the specimens $a_{0}$ at values of $33.7 \mathrm{~mm}, 34.1 \mathrm{~mm}$ and $31.4 \mathrm{~mm}$ using $G_{I I} / G_{T}$ ratios of $20 \%$, $50 \%$ and $80 \%$ respectively, with a penalty stiffness $K_{p}=$ $106 \mathrm{~N} / \mathrm{mm}^{3}$ and exponent of Benzeggagh - Kenane criterion $\eta=2.28$. The specimen had a length $2 l$ of $102 \mathrm{~mm}$, width $b$ of $25.4 \mathrm{~mm}$ and a thickness $2 h$ of $3.12 \mathrm{~mm}$, values considered also for the present simulations (Fig. 1). The density of unidirectional AS4/PEEK composite was considered as $1.48 \mathrm{~g} / \mathrm{cm}^{3}$ [24].

In Table 2 are presented all the mechanical and interfacial properties for the laminate composite considered for model validation. Here, parameter $E_{11}$ represent the
Young modulus along fibers ( $x$ direction), $E_{22}=E_{33}$ is the Young modulus across fibers ( $y$ and $z$ directions, respectively), $G_{12}, G_{13}$ and $G_{23}$ are the shear modulus along $x y, x z$ and $y z$ planes, respectively, $v_{12}, v_{13}$ and $v_{23}$ are the Poisson ratios, $N$ is the normal tensile strength and $S$ represent shear strength of the material.

Table 2

AS4/PEEK material properties considered for crack propagation modeling [22]

\begin{tabular}{|c|c|c|c|c|c|}
\hline $\begin{array}{c}E_{11}, \\
\mathrm{GPa}\end{array}$ & $\begin{array}{c}E_{22}=E_{33}, \\
\mathrm{GPa}\end{array}$ & $\begin{array}{c}G_{12}=G_{13}, \\
\mathrm{GPa}\end{array}$ & $\begin{array}{c}G_{23}, \\
\mathrm{GPa}\end{array}$ & $v_{12}=v_{13}$ & $v_{23}$ \\
\hline 122.7 & 10.1 & 5.5 & 3.7 & 0.25 & 0.45 \\
\hline $\begin{array}{c}G_{I c}, \\
\mathrm{~kJ} / \mathrm{m}^{2}\end{array}$ & $\begin{array}{c}G_{I I c}, \\
\mathrm{~kJ} / \mathrm{m}^{2}\end{array}$ & \multicolumn{2}{|c|}{$N}$, & \multicolumn{2}{|c|}{$S}$, \\
\hline 0.969 & 1.719 & \multicolumn{2}{|c|}{80} & \multicolumn{2}{c|}{100} \\
\hline
\end{tabular}

In Fig. 3a was presented the load-displacement curve predicted by the present numerical model and the experimental data [22]. A good correlation between the numerically predicted and experimentally measured maximum loads was observed here, with an error (\%) of $-2.2,-4$ and -2.6 , when $G_{I I} / G_{T}$ was 20,50 and $80 \%$, respectively.
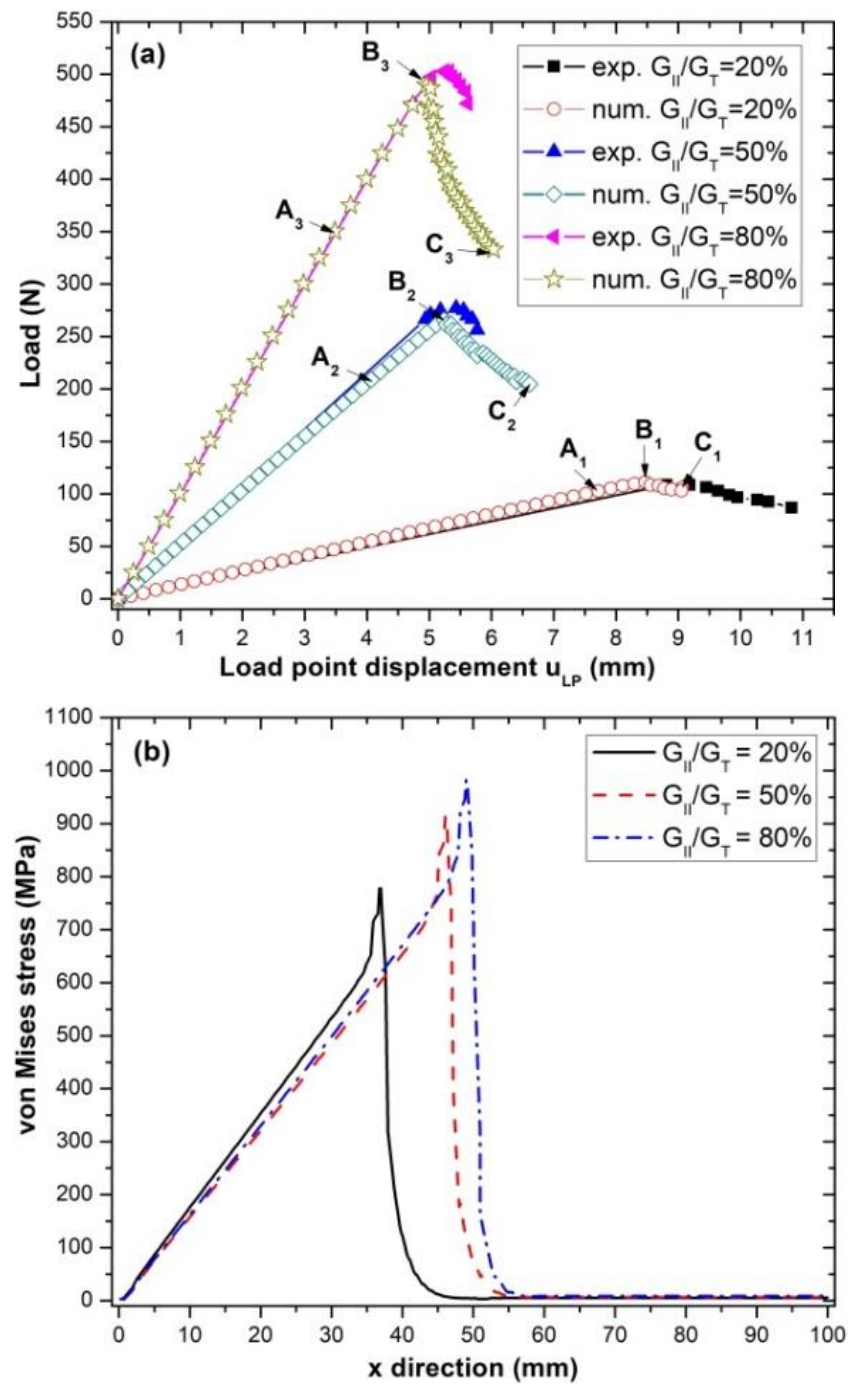

Fig. 3 a) Predicted and experimental load-displacement curves. b) von Mises stress evolution in the points $\mathrm{C}_{1}$, $\mathrm{C}_{2}$ and $\mathrm{C}_{3}$ for AS4/PEEK specimen at various $G_{I I} / G_{T}$ ratios 
From the total strain energy stored in the composite specimen as a consequence of a prescribed load - point displacement $u_{L P}$, a part goes into changing the volume of material (volumetric strain) and the other part is used to distort the shape of the material (deviatoric energy). The von Mises theory of yielding hypothesizes that material yielding will occur for a general 3D state of stress when the combination of stresses reaches the maximum distortional strain energy density [25].

Von Mises stress (related to the deviatoric energy) was evaluated along the interfaces II and V in Fig. 3, b for the identification of maximum delamination length of the specimens (equivalent to ultimate displacement): $a_{1}, a_{2}$ and $a_{3}$ in the catastrophic failure points $C_{1}, C_{2}$ and $C_{3}$ established on the load-displacement curve in Fig. 3, a.

The maximum values of stress in $C$ points: 778, 912.6 and $982 \mathrm{MPa}$ were identified at $a_{1}=36.9 \mathrm{~mm}, a_{2}=$ $=46.2 \mathrm{~mm}$ and $a_{3}=49 \mathrm{~mm}$ for $G_{I I} / G_{T}=20 \%, G_{I I} / G_{T}=50 \%$ and $G_{I I} / G_{T}=80 \%$, respectively.

Von Mises stress distributions at the points $A_{2}, B_{2}$ and $C_{2}$ labelled on the load-displacement curve is shown in Fig. 4 in order to illustrate the initiation and damage propagation (cracking) in the failure region.

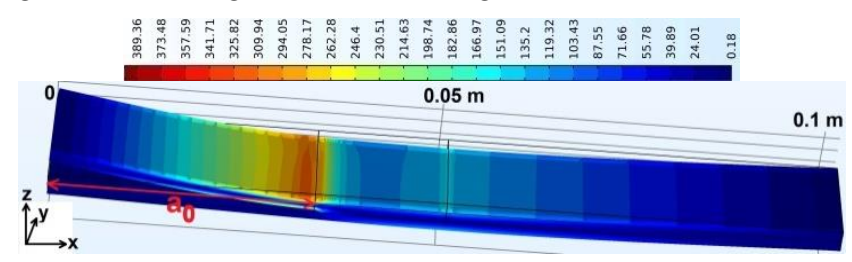

$A_{2}$

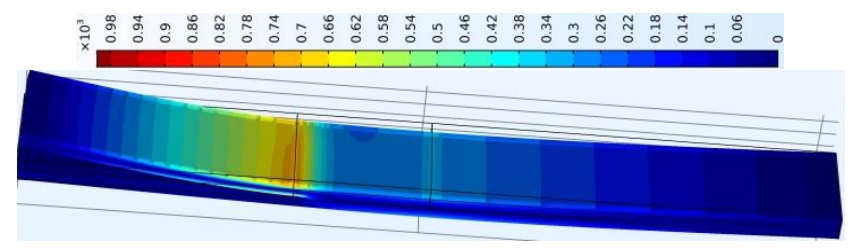

$B_{2}$

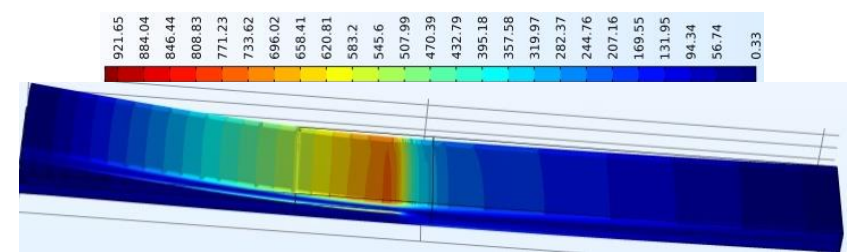

$C_{2}$

Fig. 4 Von Mises contour plots in points $A_{2}, B_{2}$ and $C_{2}$ on load - displacement curve for the AS4/PEEK composite model simulated at $G_{I I} / G_{T}=50 \%$

We could see in Fig. 4, a stress intensification at the surface of the upper ply, with maximum stress distribution located along $a_{0}$ limit ( $B_{2}$ image) and a propagation of initial crack along the interface with an area extension of delamination region $\left(C_{2}\right.$ image $)$.

In Fig. 5 are presented the variation of damage evolution function $\omega(\alpha)$ along the damage interface VI (Fig. 1) for the composite model at the three different points A, B, and $\mathrm{C}$ on the load displacement curves registered at different $G_{I I} / G_{T}$ ratios.

During the early stages of the loading at $G_{I I} / G_{T}=$ $=20 \%$ and $G_{I I} / G_{T}=50 \%$ ( $A_{1}$ and $A_{2}$ points), a maximum damage of 0.95 was detected near the initial crack edges $a_{0}$ of the specimen (Fig. 5, a and b). As the specimen is progressively stressed, the maximum damage area associated with $\omega(\alpha)=1$ moves gradually towards the specimen halflength $l$. We could see in Fig. 5, c that at the final testing stage with a displacement $u_{L P}=6.11 \mathrm{~mm}\left(C_{3}\right.$ point $)$ it was registered an extension of maximum damage area over entire region between $a_{0}$ limit and specimen half-length.
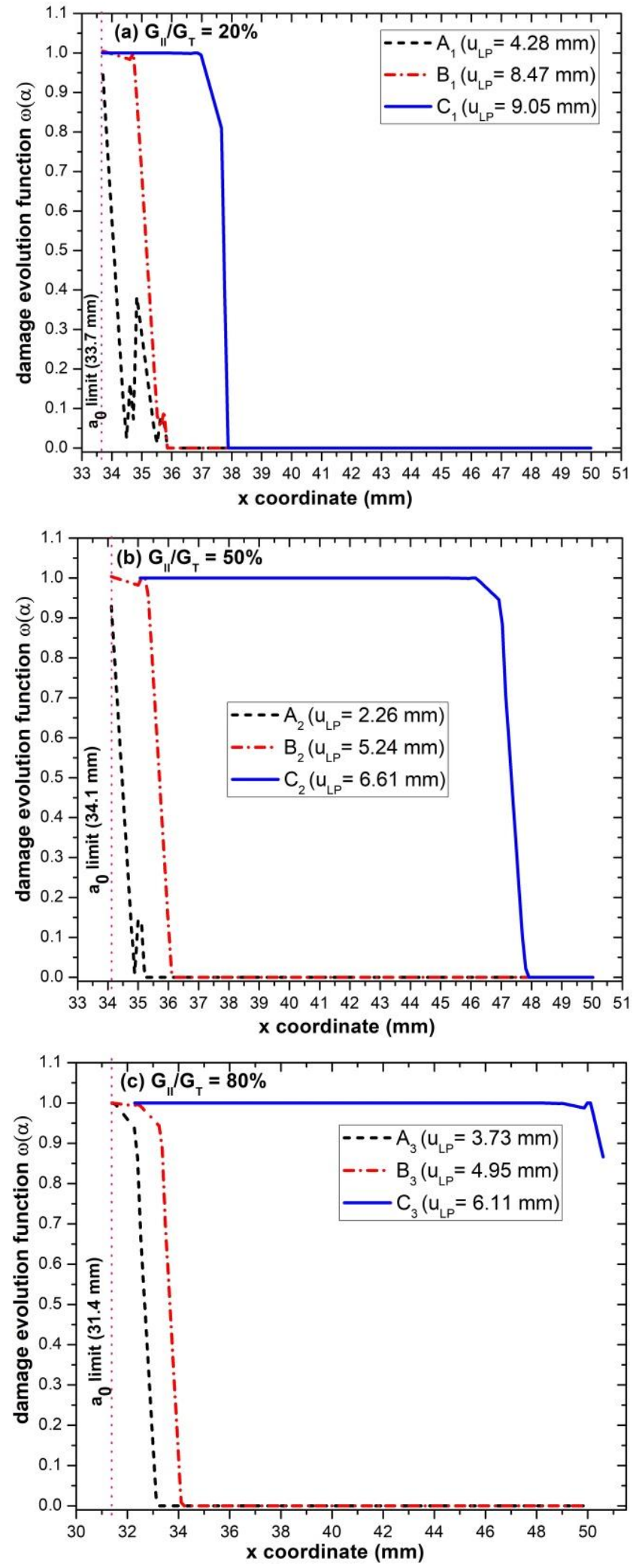

Fig. 5 Behavior of the damage evolution function along the damage interface of AS4/PEEK composite model under MMB test simulated at different $G_{I I} / G_{T}$ ratios 


\section{Conclusions}

After numerical analysis of the load-displacement curves registered at different stages of MMB test it was showed that delamination failure caused by either fiber breakage or matrix cracking in the AS4/PEEK composite FEM model occurred across the laminate where the weakest sections of these layers are located, at the interface between the two plies.

The maximum crack lengths: $a_{1}=36.9 \mathrm{~mm}, a_{2}=$ $=46.2 \mathrm{~mm}$ and $a_{3}=49 \mathrm{~mm}$ have been identified at von Mises stress values of $778 \mathrm{MPa}, 912.6 \mathrm{MPa}$ and $982 \mathrm{MPa}$ during MMB simulation test $G_{I I} / G_{T}=20 \%, G_{I I} / G_{T}=50 \%$ and $G_{I I} / G_{T}=80 \%$, respectively.

At the final stage of the MMB test simulated at $G_{I I} / G_{T}=80 \%$ for a load point displacement $u_{L P}=6.11 \mathrm{~mm}$, a damage evolution function $\omega(\alpha)=1$ was registered along the entire section between $\mathrm{a}_{0}$ limit and specimen half-width $(50 \mathrm{~mm})$, at the interface between the two plies of the structure, and a complete delamination should occur in this region.

\section{References}

1. Johnson, A. F.; Kempe, G.; Simon, J. 2000. Design of composite wing access cover under impact loads, J. Applied Composite Materials 7: 219-229. https://doi.org/10.1023/A:1008956614293.

2. Ishikawa, T.; Matsushima, M.; Hayashi, Y. 1993. Improved correlation of predicted and experimental initial buckling stresses of composite stiffened panels, Composite Structures 26(1-2): 25-38. https://doi.org/10.1016/0263-8223(93)90041-N.

3. Steinbergn, E. L.; Rath, E.; Shlaifer, A.; Chechik, O.; Maman, E.; Salai, M. 2013. Carbon fiber reinforced PEEK Optima-A composite material biomechanical properties and wear/debris characteristics of CF-PEEK composites for orthopedic trauma implants, J Mech Behav Biomed Mater. 17: 221-228. https://doi.org/10.1016/j.jmbbm.2012.09.013.

4. Li, C. S.; Vannabouathong, C.; Sprague, S.; Bhandari, M. 2015. The use of carbon-fiber-teinforced (CFR) PEEK material in orthopedic implants: a systematic review, Clin Med Insights Arthritis Musculoskelet Disord. 8: 33-45. https://doi.org/10.4137/CMAMD.S20354.

5. Asp, L. E.; Sjögren, A.; Greenhalgh, E. S. 2001. Delamination growth and thresholds in a carbon/epoxy composite under fatigue loading, Journal of Composites Technology \& Research 32(2): 55-68. https://doi.org/10.1520/CTR10914J.

6. De Morais, A. B.; Pereira, A. B. 2007. Application of the effective crack method to mode $\mathrm{i}$ and mode ii interlaminar fracture of carbon/epoxy unidirectional laminates, Composites Part A, 38: 785-794. https://doi.org/10.1016/j.compositesa.2006.09.001.

7. Wisnom, M. R. 2012. The role of delamination in failure of fibre-reinforced composites, Phil. Trans. R. Soc. A 370: 1850-1870. https://doi.org/10.1098/rsta.2011.0441.

8. Keršienè, N.; Žiliukas, A.; Keršys, A. 2010. Influence of ply orientation on mode I interlaminar fracture toughness of woven carbon and glass composites, Mechanika, 2(82): 31-36. https://doi.org/10.5755/j01.mech.82.2.15511.

9. Reeder, J. R.; Crews Jr., J. R. 1990. Mixed-mode bending method for delamination testing, AIAA Journal 28(7): 1270-1276.

https://doi.org/10.2514/3.25204.

10. Toygar, M. E.; Maleki, F. K. 2016. The temperature and pre-crack length effects on delamination resistance of woven GFRP sandwich composites, Mechanika 22(5): 331-336. https://doi.org/10.5755/j01.mech.22.5.16229.

11. Pinho, S. T.; Iannucci, L.; Robinson, P. 2006. Formulation and implementation of decohesion elements in an explicit finite element code, Compos Part A Appl. S 37(5): 778-789.

https://doi.org/10.1016/j.compositesa.2005.06.007.

12. Jiang, W. G.; Hallett S. R.; Green, B. G.; Wisnom, M. R. 2007. A concise interface constitutive law for analysis of delamination and splitting in composite materials and its application to scaled notched tensile specimens, Int. J. Numer. Methods Eng. 69 (9): 1982-1995. https://doi.org/10.1002/nme.1842.

13. Barenblatt, G. I. 1962 . The mathematical theory of equilibrium cracks in brittle fracture, Advances in Applied Mechanics 7: 55-129. https://doi.org/10.1016/S0065-2156(08)70121-2.

14. Camanho, P. P.; Davila, C. G.; de Moura, M. F. 2003. Numerical simulation of mixed mode progressive delamination in composite materials, Journal of Composite Materials 37(6): 1415-1438. https://doi.org/10.1177/0021998303034505.

15. Leckey, C. A. C.; Wheeler, K. R.; Hafiychuk, V. N.; Hafiychuk, H.; Timuçin, D. A. 2018. Simulation of guided-wave ultrasound propagation in composite laminates: Benchmark comparisons of numerical codes and experiment, Ultrasonics 84: 187-200.

https://doi.org/10.1016/j.ultras.2017.11.002.

16. Benzeggagh, M. L.; Kenane, M. 1996. Measurement of mixed-mode delamination fracture toughness of unidirectional glass/epoxy composites with mixed-mode bending apparatus, Composites Science and Technology 56: 439-449. https://doi.org/10.1016/0266-3538(96)00005-X.

17. Funari, M. F.; Greco, F., Lonetti, P. 2017. A coupled ALE-Cohesive formulation for layered structural systems, Procedia Structural Integrity 3: 362-369. https://doi.org/10.1016/j.prostr.2017.04.035.

18. Ionescu, V. 2019. Numerical Investigation of a MEMS Thermal Actuator Performance by Modifying its Geometric Dimensions, Procedia Manufacturing 32: 820830. https://doi.org/10.1016/j.promfg.2019.02.290.

19. Gasch, T.; Ericsson, D. 2017. Thermally-induced cracking of a concrete arch dam using COMSOL Multiphysics, Proceedings of the $14^{\text {th }}$ ICOLD International Benchmark Workshop on Numerical Analysis of Dams, 6-8 September 2017, Stockholm, Sweden, 1 - 11. https://oai:DiVA.org:kth-214057.

20.Zhou, S.; Zhuang, X.; Rabczuk, T. 2018. A phasefield modeling approach of fracture propagation in poroelastic media, Engineering Geology, 240: 189-203. https://doi.org/10.1016/j.enggeo.2018.04.008.

21. Coquill, S. L.; Adams, D. F. 1988. Mechanical properties of several neat polymer matrix materials and unidirectional carbon fiber-reinforced composites, NASA 
Contractor Report 181805, USA, May 1985- October 1988, $320 \mathrm{p}$.

22. Turon, A.; Camanho, P. P.; Costa, J.; Davila, C. G. 2006. A damage model for the simulation of delamination in advanced composites under variable-mode loading, Mechanics of Materials 38: 1072-1089. https://doi.org/10.1016/j.mechmat.2005.10.003.

23. Tao, C.; Qiu, J.; Yao, W.; Ji, H. 2016. A novel method for fatigue delamination simulation in composite laminates, Composites Science and Technology 128: 104115.

https://doi.org/10.1016/j.compscitech.2016.03.016.

24. Schulte K. J.; Hahn H. T. 1989. Prediction and control of processing-induced residual stresses in composites part II: AS4/PEEK composite, Final technical report, Grant: AFOSR-87-0242, Pennsylvania State University, USA, October 1989, 7.

25. Hibbeler R. C. 2017. Mechanics of Materials, $10^{\text {th }}$ ed., Pearson Education, Hoboken, NJ. 896 p.
V. Ionescu

\section{FEM MODELING OF DELAMINATION IN AS4/PEEK THERMOPLASTIC COMPOSITES UNDER MIXED - MODE BENDING TEST}

S u m m a r y

Interfacial failure by delamination in the unidirectional AS4/PEEK laminated composite was simulated through this paper with a finite element method (FEM) based model developed with Comsol Multiphysics software. The mixed - mode bending (MMB) test was investigated numerically here after a successful validation of the model by comparing with experimental measurements of the load-displacement curve provided in the literature. The maximum delamination length of the specimens modeled, the corresponding von Mises stress distributions and the damage evolution function have been evaluated for different ratios between mode II strain energy rate and total strain energy rate $G_{I I} / G_{T}=20,50$ and $80 \%$.

Keywords: upper ply, fracture toughness, delamination length, stress. 